\title{
Serum Adiponectin and Progranulin Level in Patients with Benign Thyroid Nodule or Papillary Thyroid Cancer
}

\author{
Hyemi Kwon ${ }^{1}$, Se Eun Park ${ }^{1}$, Ji-Sup Yun², Cheol-Young Park ${ }^{1}$ \\ ${ }^{1}$ Division of Endocrinology and Metabolism, Department of Internal Medicine, ${ }^{2}$ Department of Surgery, Kangbuk Samsung \\ Hospital, Sungkyunkwan University School of Medicine, Seoul, Korea
}

Background: Obesity is associated with thyroid cancer risk. Adiponectin has insulin-sensitizing and anti-inflammatory effects, while progranulin is associated with inflammation and tumorigenesis. We investigated serum adiponectin and progranulin levels in patients with benign thyroid nodule (benign group) and papillary thyroid cancer (PTC; PTC group). The associations between these levels and the clinicopathological features of PTC were evaluated.

Methods: We included 157 patients who underwent thyroid surgery (17\% of benign and $83 \%$ of PTC group). Clinicopathological features including size, lymph node metastasis, extrathyroidal extension (ETE), multifocality, American Thyroid Association risk stratification were evaluated.

Results: The age was 42.0 years, and $69 \%$ were female. Serum adiponectin and progranulin levels were $6.3 \mu \mathrm{g} / \mathrm{mL}$ and $101.5 \mathrm{ng} / \mathrm{mL}$ in the benign group and $5.4 \mu \mathrm{g} / \mathrm{mL}$ and $106.1 \mathrm{ng} / \mathrm{mL}$ in the PTC group, respectively ( $P=0.6$ and $P=0.4$, respectively). Serum adiponectin levels showed no significant differences according to clinicopathological features of PTC. The proportions of patients with primary tumor size $>1 \mathrm{~cm}$ were $3 \%, 5 \%, 8 \%$, and $8 \%$ according to serum progranulin level quartiles, respectively $(P=0.03)$. The proportions of patients with microscopic/gross ETE were $8 \% / 0 \%, 9 \% / 1 \%, 11 \% / 1 \%$, and $11 \% / 2 \%$ according to serum progranulin level quartiles, respectively. Median serum progranulin level was significantly higher in patients with PTC $>1 \mathrm{~cm}$ than in patients with papillary thyroid microcarcinoma $(P=0.04,115.3 \mathrm{ng} / \mathrm{mL}$ and $104.7 \mathrm{ng} / \mathrm{mL}$, respectively).

Conclusion: Serum adiponectin and progranulin levels showed no significant difference between benign and PTC groups. Increased serum progranulin levels were significantly associated with PTC $>1 \mathrm{~cm}$ and microscopic and gross ETE.

Keywords: Obesity; Thyroid neoplasms; Adiponectin; Progranulins

\section{INTRODUCTION}

Obesity is characterized by excessive accumulation of body fat and is a risk factor for several cancers including breast cancer,

Received: 6 November 2019, Revised: 30 April 2020, Accepted: 4 May 2020 Corresponding authors: Ji-Sup Yun

Department of Surgery, Kangbuk Samsung Hospital, Sungkyunkwan University School of Medicine, 29 Saemunan-ro, Jongno-gu, Seoul 03181, Korea

Tel: +82-2-2001-1730, Fax: +82-2-2001-1883, E-mail: jisup.yun@samsung.com

Cheol-Young Park

Division of Endocrinology and Metabolism, Department of Internal Medicine, Kangbuk Samsung Hospital, Sungkyunkwan University School of Medicine, 29 Saemunan-ro, Jongno-gu, Seoul 03181, Korea

Tel: +82-2-2001-1552, Fax: +82-2-2001-1588, E-mail: cydoctor@chol.com endometrial cancer, colon cancer, and prostate cancer [1-4]. Previous studies have also demonstrated the association between obesity and increased risk of thyroid cancer [4-10]. Though the underlying mechanisms have not yet fully under-

\section{Copyright $\odot 2020$ Korean Endocrine Society}

This is an Open Access article distributed under the terms of the Creative Commons Attribution Non-Commercial License (https://creativecommons.org/ licenses/by-nc/4.0/) which permits unrestricted non-commercial use, distribution, and reproduction in any medium, provided the original work is properly cited. 
stood, obesity-related metabolic abnormalities including chronic inflammation, insulin resistance, and several adipokines have been suggested to contribute to the association between obesity and cancer risk [1,10-17].

Adiponectin is an adipokine inversely associated with obesity and insulin resistance $[17,18]$. It has insulin-sensitizing, anti-inflammatory, and anti-atherogenic effects and has been suggested to be a biological mediator between obesity and the increased risk of several cancers $[18,19]$. Several studies have reported that serum adiponectin level has been suggested independently and inversely associated with risk of thyroid cancer $[17,18]$. In addition, a case-control study reported human thyroid carcinomas and cell lines express adiponectin receptors [19]. However, the association between serum adiponectin level and clinicopathological features of thyroid cancer has been little studied [20]. One study reported that serum adiponectin levels were similar between patients with and without any type of invasion or metastasis, including bilaterality, multifocality, cervical lymph node (LN) metastasis, extrathyroidal invasion, vascular invasion, and distant metastasis [20].

Progranulin is a cysteine-rich secreted protein with diverse pleiotropic actions and participates in several processes, such as inflammation and tumorigenesis [21]. Progranulin has been recognized as an adipokine related to obesity and insulin resistance [22]. Progranulin has been proposed to be associated with the development and progression of several types of obesity-associated cancers such as breast cancer and prostate cancer [21,2328]. However, serum progranulin level in patients with thyroid cancer has not been investigated, although obesity is associated with the risk of thyroid cancer [4-10].

In this study, we investigated serum adiponectin and progranulin levels in patients with benign thyroid nodule or papillary thyroid cancer (PTC). We also evaluated the association between serum adiponectin and progranulin levels and the clinicopathological features of PTCs.

\section{METHODS}

\section{Study design and patients}

This study included 157 patients who underwent thyroid surgery due to benign thyroid nodule or PTC in Kangbuk Samsung Hospital between July 2011 and October 2011. Of the 157 patients, $17 \%$ had benign thyroid nodule (benign group) and $83 \%$ had PTC (PTC group). Serum adiponectin and progranulin levels were evaluated in benign and PTC groups. Subjects who agreed to join this study and who were at least 20 years of age were included. This study was approved by the Institutional Review Board of Kangbuk Samsung Hospital (KBC11082), and informed consent was obtained from all participants.

\section{Anthropometric measurements}

On the day of admission for thyroid surgery, the heights and weights were measured in patients wearing light clothing without shoes. Body mass index (BMI) was calculated using the following formula; the weight in kilograms stratified by the square of the height in meters $\left(\mathrm{kg} / \mathrm{m}^{2}\right)$.

\section{Blood collection and laboratory analyses}

Blood specimens were taken from the antecubital vein of subjects following a fast of at least 10 hours early in the morning before thyroid surgery. Serum adiponectin and progranulin levels were measured using a commercial kit of enzyme-linked immunosorbent assay (AdipoGen Inc., San Diego, CA, USA) according to the manufacturer's instructions.

\section{Management protocol and definition}

All the patients underwent routine preoperative neck ultrasonography. The surgical extent was determined depending on the clinicopathological risk factors, the decision of the physician, and patient preference. For patients who underwent lobectomy, routine prophylactic ipsilateral central compartment LN dissection was performed. For patients who underwent total thyroidectomy, prophylactic ipsilateral or bilateral central compartment LN dissection was performed. Therapeutic neck dissection was performed when metastatic cervical LNs were suspected or confirmed preoperatively. The definition of papillary thyroid microcarcinoma (PTMC) is a PTC of $1 \mathrm{~cm}$ or less. The risk stratification suggested by the American Thyroid Association (ATA) was applied to compare serum adiponectin and progranulin levels between the patients with ATA low and ATA intermediate/high risk [29].

\section{Statistical analysis}

For statistical analysis, IBM SPSS Statistics for Window version 24.0 (IBM Co., Armonk, NY, USA) was used. Continuous variables are expressed as median with interquartile range (IQR). Categorical variables are presented as number and percentage. The Mann-Whitney $U$ test, Kruskal-Wallis test, Pearson correlation analysis, Fisher's exact test, and linear by linear association were used. A $P<0.05$ was considered statistically significant. All $P$ values were 2 -sided. 


\section{RESULTS}

\section{Baseline characteristics of the patients}

This study included 157 patients. Baseline characteristics of the patients are listed in Table 1. Median age was 42.0 years (IQR, 34.0 to 50.0 ) and $69 \%$ were female. Median height and weight were $163.3 \mathrm{~cm}$ (IQR, 159.4 to 170.5 ) and $61.7 \mathrm{~kg}$ (IQR, 56.1 to 71.6). Median BMI was $23.7 \mathrm{~kg} / \mathrm{m}^{2}$ (IQR, 21.0 to 25.8). Median adiponectin and progranulin levels were $5.5 \mu \mathrm{g} / \mathrm{mL}$ (IQR, 2.7 to 9.9) and $105.8 \mathrm{ng} / \mathrm{mL}$ (IQR, 91.1 to 124.5$)$, respectively.

In total, $17 \%$ of patients had benign thyroid nodule (benign group) and $83 \%$ of patients had PTC (PTC group). In the PTC group, the median primary tumor size was $0.7 \mathrm{~cm}$ (IQR, 0.5 to 1.1 ) and $25 \%$ showed primary tumor size $>1.0 \mathrm{~cm}$ (Table 1 ). Among the 72 patients (55\%) with cervical LN metastasis, 59 patients $(45 \%)$ had N1a and 13 patients $(10 \%)$ had N1b of cervical LN metastasis. Among the 58 patients (45\%) with the extrathyroidal extension (ETE), 53 patients (41\%) had microscopic ETE and five patients (4\%) had gross ETE. The proportion of patients with multifocal PTC was $21 \%$. In the PTC group, 65 patients (49\%) had ATA low risk and 66 patients $(51 \%)$ had ATA intermediate/high risk.

\section{Anthropometric markers and serum adiponectin and progranulin levels.}

Age, sex, height, weight, and BMI were compared between benign and PTC groups and there were no significant differences (Table 1). When we performed correlation analysis, BMI and serum adiponectin levels had a weak negative association $(r=$ $-0.143)$ which was not statistically significant $(P=0.074)$. The correlation between BMI and serum progranulin levels showed no significant association either $(r=0.075, P=0.4)$.

\section{Serum adiponectin and progranulin level in patients with benign thyroid nodule or PTC}

Median serum adiponectin level was $6.3 \mu \mathrm{g} / \mathrm{mL}$ (IQR, 3.1 to 10.2) in the benign group and $5.4 \mu \mathrm{g} / \mathrm{mL}$ (IQR, 2.7 to 9.6 ) in the PTC group (Fig. 1A). Serum adiponectin level had no statistically significant differences between the benign and PTC groups $(P=$ 0.6). Median serum progranulin level was $101.5 \mathrm{ng} / \mathrm{mL}$ (IQR,

\begin{tabular}{|c|c|c|c|c|}
\hline Characteristic & Total $(n=157)$ & Benign $(n=26)$ & $\operatorname{PTC}(n=131)$ & $P$ value \\
\hline Age, yr & $42(34-50)$ & $48(35-53)$ & $41(33-48)$ & 0.1 \\
\hline Female sex & 109 (69) & $17(65)$ & $92(70)$ & 0.6 \\
\hline Height, cm & $163.3(159.4-170-5)$ & $162.9(160.9-172.6)$ & $163.3(158.9-169.8)$ & 0.5 \\
\hline Weight, kg & $61.7(56.1-71.6)$ & $65(55.1-72.0)$ & $61.6(56.1-71.4)$ & 0.9 \\
\hline BMI, $\mathrm{kg} / \mathrm{m}^{2}$ & $23.7(21.0-25.8)$ & $23.5(20.9-26.0)$ & $23.7(21.0-25.8)$ & 0.9 \\
\hline \multicolumn{5}{|c|}{ Clinicopathological features of PTC } \\
\hline Size, $\mathrm{cm}$ & & & $0.7(0.5-1.1)$ & \\
\hline$>1 \mathrm{~cm}$ (yes) & & & $33(25)$ & \\
\hline LN metastasis (yes) & & & $72(55)$ & \\
\hline N1a & & & $59(45)$ & \\
\hline N1b & & & $13(10)$ & \\
\hline ETE (yes) & & & $58(45)$ & \\
\hline Microscopic ETE (yes) & & & $53(41)$ & \\
\hline Gross ETE (yes) & & & $5(4)$ & \\
\hline Multifocality (yes) & & & $28(21)$ & \\
\hline \multicolumn{5}{|l|}{ ATA risk stratification } \\
\hline Low risk & & & $65(49)$ & \\
\hline Intermediate/high risk & & & $66(51)$ & \\
\hline Adiponectin, $\mu \mathrm{g} / \mathrm{mL}$ & $5.5(2.7-9.7)$ & $6.3(3.1-10.2)$ & $5.4(2.7-9.6)$ & 0.6 \\
\hline Progranulin, ng/mL & $105.8(91.5-124.2)$ & $101.5(79.4-125.4)$ & $106.1(94.1-123.9)$ & 0.4 \\
\hline
\end{tabular}

Values are expressed as median (interquartile range) or number (\%).

PTC, papillary thyroid cancer; BMI, body mass index; LN, lymph node; ETE, extrathyroidal extension; ATA, American Thyroid Association. 

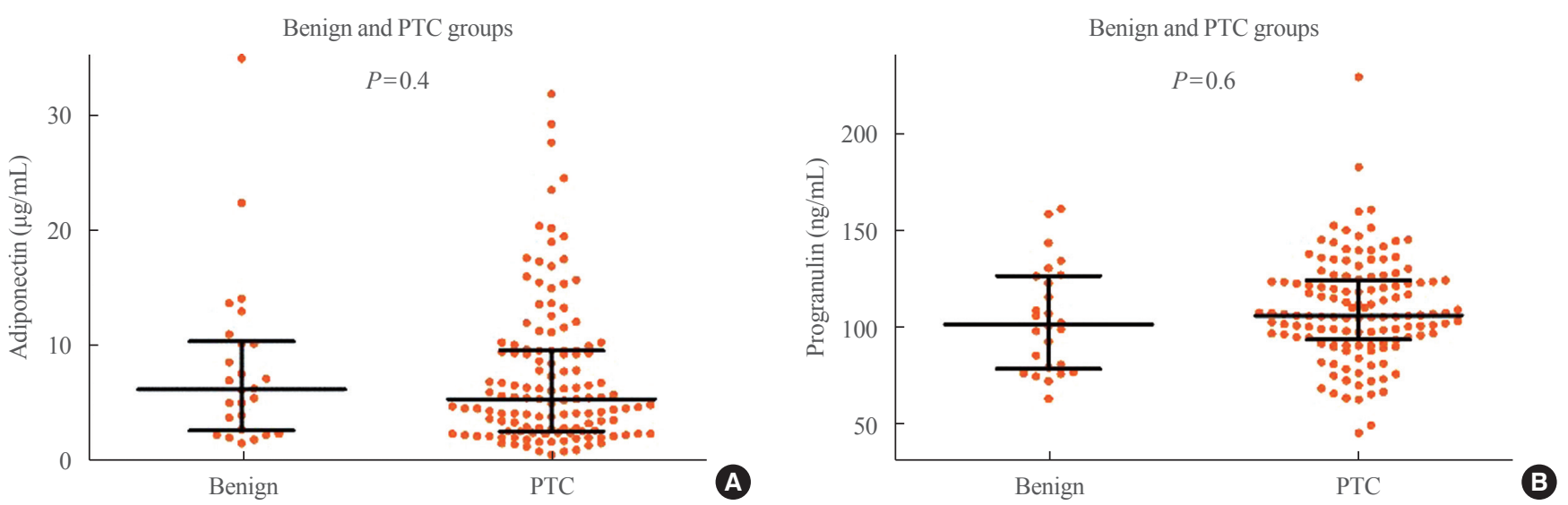

Fig. 1. (A) Serum adiponectin level in patients with benign thyroid nodule or papillary thyroid cancer (PTC). (B) Serum progranulin level in patients with benign thyroid nodule or papillary thyroid cancer. Error bars show medians and interquartile ranges.

Table 2. Clinicopathological Features According to Serum Adiponectin and Progranulin Levels Quartiles in Patients with Papillary Thyroid Cancer

\begin{tabular}{|c|c|c|c|c|c|c|}
\hline Variable & Total $(n=131)$ & Q1 & Q2 & Q3 & Q4 & $P$ value \\
\hline \multicolumn{7}{|c|}{ Serum adiponectin level quartiles } \\
\hline Size $>1 \mathrm{~cm}$ & $33(25)$ & $9(7)$ & $8(6)$ & $6(5)$ & $10(8)$ & 0.7 \\
\hline LN metastasis (yes) & $72(55)$ & $22(17)$ & $20(15)$ & $12(9)$ & $18(14)$ & 0.3 \\
\hline N1a & $59(45)$ & $17(13)$ & $19(15)$ & $9(7)$ & $14(11)$ & 0.7 \\
\hline $\mathrm{N} 1 \mathrm{~b}$ & $13(10)$ & $5(4)$ & $1(1)$ & $3(2)$ & $4(3)$ & \\
\hline ETE (yes) & $58(45)$ & $12(9)$ & $18(14)$ & $10(8)$ & $18(14)$ & 0.2 \\
\hline Microscopic ETE & $53(41)$ & $11(8)$ & $16(12)$ & $9(7)$ & $17(13)$ & 0.3 \\
\hline Gross ETE & $5(4)$ & $1(1)$ & $2(4)$ & $1(1)$ & $1(1)$ & \\
\hline Multifocality (yes) & $28(21)$ & $5(4)$ & $5(4)$ & $8(6)$ & $10(8)$ & 0.05 \\
\hline ATA risk stratification & & & & & & 0.3 \\
\hline Low risk & $65(49)$ & $19(15)$ & $15(11)$ & $20(15)$ & $11(8)$ & \\
\hline Intermediate/high risk & $66(51)$ & $15(11)$ & $19(15)$ & $12(9)$ & $20(15)$ & \\
\hline \multicolumn{7}{|c|}{ Serum progranulin level quartiles } \\
\hline Size $>1 \mathrm{~cm}$ & $33(25)$ & $4(3)$ & $7(5)$ & $11(8)$ & $11(8)$ & 0.03 \\
\hline LN metastasis (yes) & $72(55)$ & $14(11)$ & $22(17)$ & $14(11)$ & $22(17)$ & 0.3 \\
\hline N1a & $59(45)$ & $12(9)$ & $18(14)$ & $12(9)$ & $17(13)$ & 0.6 \\
\hline N1b & $13(10)$ & $2(2)$ & $4(3)$ & $2(2)$ & $5(4)$ & \\
\hline ETE (yes) & $58(45)$ & $11(8)$ & $13(10)$ & $16(12)$ & $18(14)$ & 0.08 \\
\hline Microscopic ETE & $53(41)$ & $11(8)$ & $12(9)$ & $15(11)$ & $15(11)$ & 0.03 \\
\hline Gross ETE & $5(4)$ & 0 & $1(1)$ & $1(1)$ & $3(2)$ & \\
\hline Multifocality (yes) & $28(21)$ & $8(6)$ & $6(5)$ & $6(5)$ & $8(6)$ & 0.9 \\
\hline ATA risk stratification & & & & & & 0.2 \\
\hline Low risk & $65(49)$ & $17(13)$ & $19(15)$ & $16(12)$ & $13(10)$ & \\
\hline Intermediate/high risk & $66(51)$ & $13(10)$ & $16(12)$ & $18(14)$ & $19(15)$ & \\
\hline
\end{tabular}

Values are expressed as number (\%). $P$ values were calculated by linear by linear association.

LN, lymph node; ETE, extrathyroidal extension; ATA, American Thyroid Association. 
79.4 to 125.4 ) in the benign group and $106.1 \mathrm{ng} / \mathrm{mL}$ (IQR, 94.1 to 123.9) in the PTC group (Fig. 1B). Serum progranulin level did not differ significantly between the benign and PTC groups $(P=0.4)$.

\section{Clinicopathological features according to serum adiponectin and progranulin level quartiles}

Clinicopathological features were analyzed according to serum adiponectin and progranulin level quartiles in patients with PTC (Table 2). The proportions of patients with primary tumor size $>1 \mathrm{~cm}$, cervical LN metastasis including N1a and N1b, ETE including microscopic and gross ETE, multifocality, and ATA risk stratification did not have significant differences according to serum adiponectin level quartiles.

The numbers of patients with primary tumor size $>1 \mathrm{~cm}$ were four $(3 \%)$, seven $(5 \%), 11(8 \%)$, and $11(8 \%)$ according to serum progranulin level quartiles, respectively, and these increased significantly according to serum progranulin level quartiles $(P=0.03)$. The numbers of patients with microscopic ETE were $11(8 \%), 12(9 \%), 15(11 \%)$, and $15(11 \%)$ according to serum progranulin level quartiles, respectively. The numbers of patients with gross ETE were $0(0 \%)$, one $(1 \%)$, one $(1 \%)$, and three $(2 \%)$ according to serum progranulin level quartiles, respectively. The proportions of patients with microscopic and gross ETE increased significantly according to serum progranulin level quartiles $(P=0.03)$. The proportions of patients with cervical LN metastasis including N1a and N1b, multifocality, ATA risk stratification did not have significant differences according to serum progranulin level quartiles.
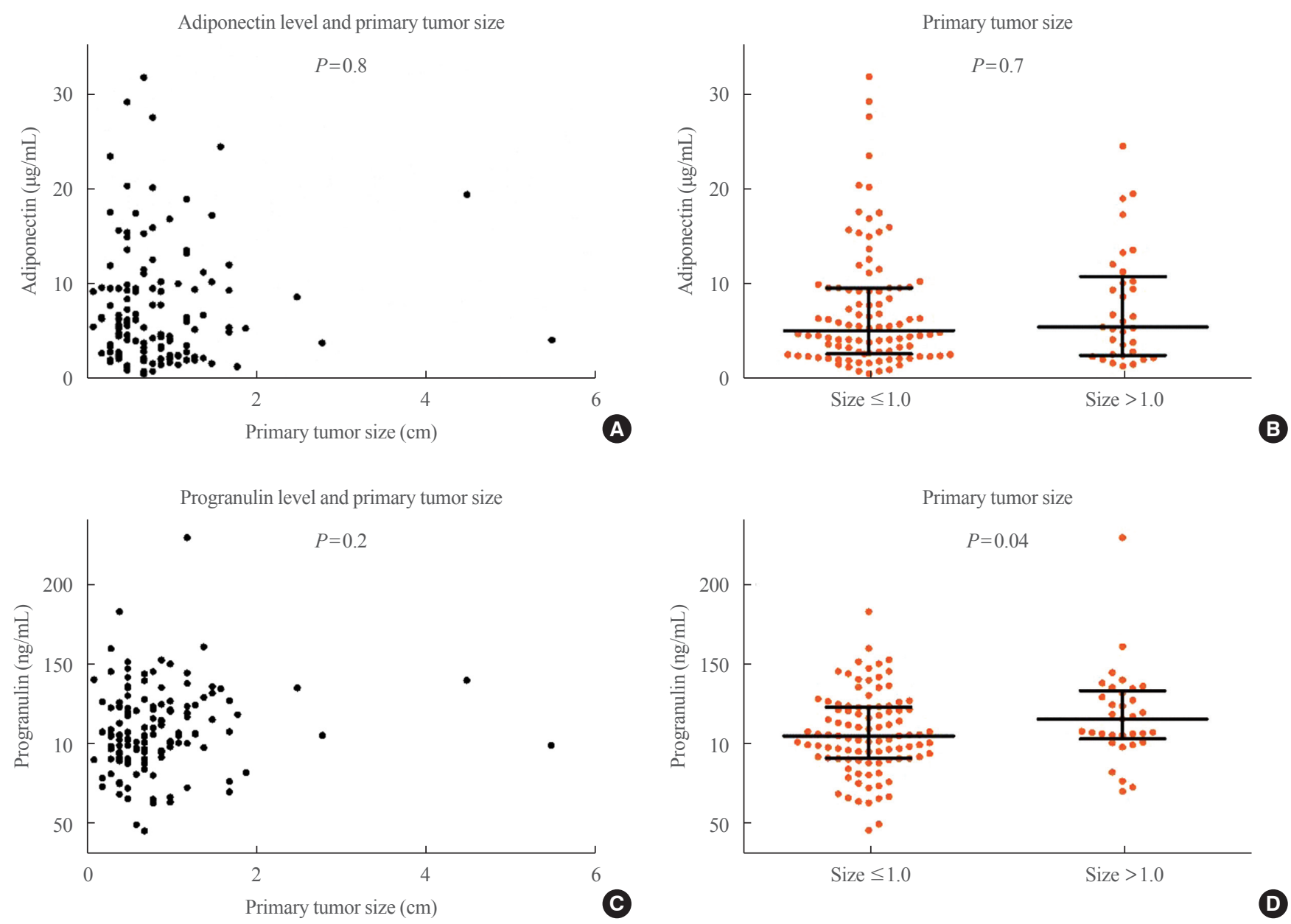

Fig. 2. (A) Correlation analysis between serum adiponectin level and primary tumor size in patients with papillary thyroid cancer (PTC). (B) Serum adiponectin level in patients with papillary thyroid microcarcinoma (PTMC) and PTC $>1 \mathrm{~cm}$. (C) Correlation analysis between serum progranulin level and primary tumor size in patients with papillary thyroid cancer. (D) Serum progranulin level in patients with PTMC and PTC $>1 \mathrm{~cm}$. Error bars of (B) and (D) show medians and interquartile ranges. 


\section{Serum adiponectin level according to clinicopathological feature of PTC}

Fig. 2A shows the association between serum adiponectin level and primary tumor size in the PTC group. There was no significant correlation between serum adiponectin level and the primary tumor size $(P=0.8)$. Median serum adiponectin level was $5.2 \mu \mathrm{g} / \mathrm{mL}$ (IQR, 2.7 to 9.6) in patients with PTMC and $5.5 \mu \mathrm{g} / \mathrm{mL}$ (IQR, 2.6 to 10.8) in patients with PTC $>1 \mathrm{~cm}(P=0.7)$ (Fig. 2B). Serum adiponectin level in patients with PTC showed no significant difference according to presence of cervical LN metastasis, ETE, or multifocality $(P=0.6$, Fig. 3A; $P=0.7$, Fig. 3B; $P=0.09$, Fig. $3 \mathrm{C}$, respectively). Serum adiponectin level was not associated with metastatic $\mathrm{LN}$ ratio in patients with central $\mathrm{LN}$ metastasis $(P=0.5)$. Median serum adiponectin level was $5.0 \mu \mathrm{g} / \mathrm{mL}$ (IQR, 2.6 to 9.4) in patients with ATA low risk and $5.5 \mu \mathrm{g} / \mathrm{mL}$ (IQR, 3.4 to 11.4 ) in patients with ATA intermediate/high risk. There was no significant difference in serum adiponectin level in patients with ATA low or ATA intermediate/high risk $(P=0.4$, Fig. 3D).

\section{Serum progranulin level according to clinicopathological feature of PTC}

Fig. 2C shows the association between serum progranulin level and primary tumor size in the PTC group. There was no significant correlation between serum progranulin level and the primary tumor size $(P=0.2)$. Median serum progranulin level was significantly higher in patients with PTC $>1 \mathrm{~cm}$ than in patients with PTMC (115.3 ng/mL [IQR, 102.8 to 133.2] and $104.7 \mathrm{ng} / \mathrm{mL}$ [IQR, 90.5 to 122.7], respectively; $P=0.04$ ) (Fig. 2D). Serum progranulin level in patients with PTC showed no significant difference according to presence of cervical LN metastasis, ETE, or multifocality $(P=0.8$, Fig. $4 \mathrm{~A} ; P=0.2$, Fig. $4 \mathrm{~B} ; P=0.6$, Fig. $4 \mathrm{C}$, respectively). Serum progranulin level was not associated with metastatic LN ratio in patients with central LN metastasis
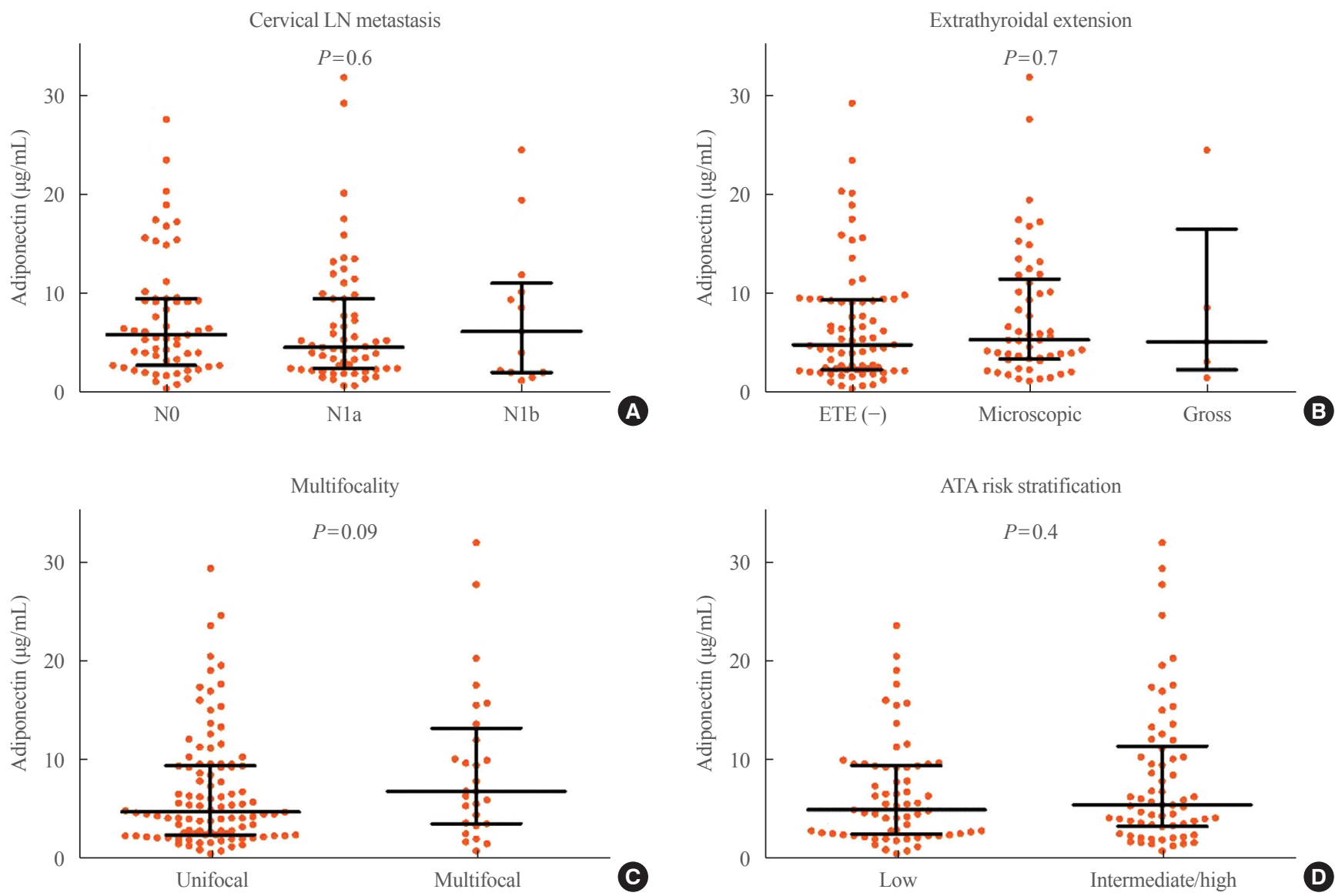

Fig. 3. Serum adiponectin level in patients with papillary thyroid cancer (PTC) according to (A) cervical lymph node metastasis, (B) extrathyroidal extension, (C) multifocality, and (D) American Thyroid Association (ATA) risk stratification. Error bars mean medians and interquartile ranges. 

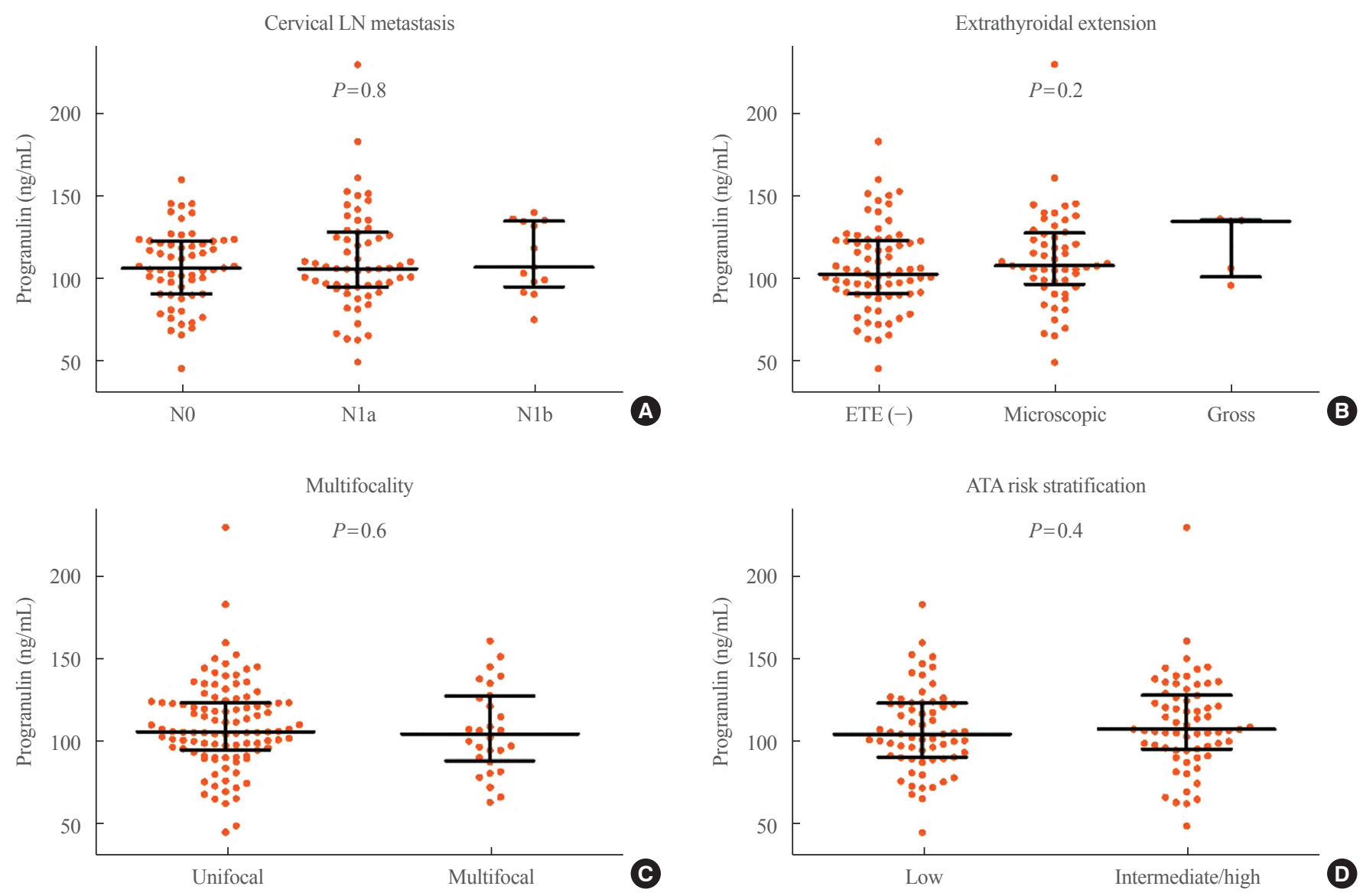

Fig. 4. Serum progranulin level in patients with papillary thyroid cancer (PTC) according to (A) cervical lymph node metastasis, (B) extrathyroidal extension, (C) multifocality, and (D) American Thyroid Association (ATA) risk stratification. Error bars mean medians and interquartile ranges. LN, lymph node.

$(P=0.3)$. Median serum progranulin level was $104.7 \mathrm{ng} / \mathrm{mL}$ (IQR, 90.6 to 123.3 ) in patients with ATA low risk and $107.6 \mathrm{ng} / \mathrm{mL}$ (IQR, 95.5 to 128.2) in patients with ATA intermediate/high risk. There was no significant difference in serum progranulin levels in patients with ATA low or ATA intermediate/high risk $(P=0.4$, Fig. 4D).

\section{DISCUSSION}

In this study, serum adiponectin and progranulin level did not have significant differences between benign and PTC groups. When clinicopathological features were evaluated according to serum adiponectin and progranulin level quartiles in patients with PTC, the proportions of patients with primary tumor size $>1 \mathrm{~cm}$ and microscopic and gross ETE increased significantly according to serum progranulin level quartiles. The median serum progranulin level was significantly higher in patients with
PTC $>1 \mathrm{~cm}$ than in patients with PTMC. However, serum adiponectin level showed no significant differences according to the clinicopathological features of PTC.

The incidence of thyroid cancer has been increasing throughout the world during the last few decades [30-33]. During the same time period, the prevalence of obesity has dramatically increased and has become a major public health issue worldwide $[34,35]$. In addition to the widespread use of high-resolution imaging tools, changes in lifestyle and environmental factors are considered contributing factors to an increase in the incidence of thyroid cancer $[33,36]$. Obesity has been associated with increased risk of thyroid cancer [4-10]. The expanding adipose tissue in obesity could contribute to development of cancer by dysregulated secretion of adipokines because adipose tissue is an active endocrine organ that produces and releases adipokines [14,37,38].

Decreased level of adiponectin, which is one of adipokines, is 
also reported to be a risk factor for obesity-related cancers including breast cancer, prostate cancer, and colorectal cancers $[14,18,19]$. The anti-tumor effects of adiponectin may be caused indirectly by decreasing insulin resistance, hyperinsulinemia, and insulin-like growth factor-1 or by modulating neovascularization and inflammation [18]. Considering that several cancer cells express adiponectin receptors, adiponectin may be able to act directly on tumor cells [18,39].

Several studies have reported that serum adiponectin level has been suggested inversely associated with risk of thyroid cancer $[17,18]$. However, this study did not show significant differences of serum adiponectin level between the benign and PTC groups. In addition, the median serum adiponectin level in this study $(5.5 \mu \mathrm{g} / \mathrm{mL})$ was lower than that of the previous study (17.0 to $19.3 \mu \mathrm{g} / \mathrm{mL}$ ) [18]. It might be one reason for this different result that BMIs of the study patients in this study were lower than those in the previous studies. The median BMI of the study patients was $23.7 \mathrm{~kg} / \mathrm{m}^{2}$ in this study; however, it was 25.5 to $29.5 \mathrm{~kg} / \mathrm{m}^{2}$ in the previous studies $[17,18]$. The small number of study subjects could be another reason for the discrepancy. In particular, it is one of the limitations of this study that the number of patients with benign thyroid nodule was small. Different pathologic types of thyroid cancers included in the study could be another reason. This study included only patients with PTC. In contrast, the previous studies included follicular, medullary, and Hurthle cell thyroid cancer as well as PTC $[17,18]$. On subgroup analysis of the previous study, subjects in the highest tertile of serum adiponectin levels had significantly lower odds of developing PTC compared with subjects in the lowest tertile [18]. A case-control study including patients with medullary thyroid carcinoma (MTC), serum adiponectin level was not significantly different between the MTC and healthy control groups [40].

The association between serum adiponectin level and clinicopathological features of thyroid cancer has been little studied [20]. This study demonstrated serum adiponectin level showed no significant differences according to the clinicopathological features of PTC, consistent with the previous study [20]. In a study evaluating expression of adiponectin receptors in the tumor tissues of PTC, negative expression of adiponectin receptors was significantly associated with extrathyroidal invasion, multicentricity, and higher tumor-node-metastasis (TNM) stage [19]. These results suggested that the expression of adiponectin receptors rather than serum adiponectin levels may be associated with the progression of thyroid cancer.

Progranulin is an adipokine also known as acrogranin, granu- lin/epithelin precursor, proepithelin, PC cell-derived growth factor, and 88-kDa glycoprotein (GP88) [23,24]. Progranulin has been implicated in multiple biological and pathological processes of cell growth, tumorigenesis, embryogenesis, wound healing, inflammation, immunity, and insulin resistance [21]. Overexpression of progranulin has been detected in several cancer tissues including breast cancer, ovarian cancer, and cholangiocarcinoma [21,23-28]. Increased expression of progranulin promotes responses such as proliferation, invasion and migration, angiogenesis, malignant transformation, and immune evasion that can lead to development of cancers [24].

Because progranulin is a secreted protein, circulating level of progranulin can be measured using an enzyme immunoassay. This is the first study to evaluate serum progranulin level in patients with thyroid cancer, which is known as the obesity-related cancer. In this study, serum progranulin levels increased significantly in patients with PTC $>1 \mathrm{~cm}$ and microscopic and gross ETE. However, there was no significant difference in serum progranulin level between benign and PTC groups. These results suggested that serum progranulin level is likely to be associated with the progression rather than the development of thyroid cancer.

Serum progranulin level has been evaluated in several cancers [21,23-28]. The previous studies showed inconsistent results in the role of progranulin for cancer. In a study of ovarian cancer, serum progranulin levels were not significantly increased in patients with ovarian cancer compared with benign disease [25]. However, increased serum progranulin level was associated with decreased overall survival in advanced ovarian cancer [25]. These results suggested that serum progranulin level was associated with the progression rather than the development of cancer. In contrast, another study of breast cancer reported that serum progranulin level was elevated in patients with breast cancer than in healthy volunteers, and it was higher in patients with later stage than early stage [27]. These results supported that serum progranulin level was associated with the progression as well as the development of cancer. Further studies about progranulin in thyroid cancer are needed to clearly understand their association.

This study has several limitations. The possibility of selection bias cannot be ruled out because patients from a single tertiary referral center were enrolled. We only included patients with a benign thyroid nodule or PTC, there were not healthy controls. Also, the data of age- and sex-matched normal controls was unavailable, the analysis of age- and sex-matched normal controls could not be performed. The small number of study subjects, 
especially the small number of patients with benign thyroid nodule was one of the limitations of our study. The proportion of patients with benign thyroid disease was relatively small since only patients who underwent thyroid surgery were enrolled. Correlation analysis between BMI and serum adiponectin or progranulin levels showed no significant association either. This is a limitation of our study and it may be because this study included a relatively small number of patients. It may be one of the causes in which this study has not shown statistically significant associations contrary to previous studies. Because we included patients who underwent thyroid surgery in 2011, approximately $70 \%$ of patients in the PTC group had PTMCs. We could not obtain information on body composition or homeostatic model assessment of insulin resistance for the measurement of insulin resistance in the patients. Because this study included a relatively small number of patients with a benign thyroid nodule and PTC, it is hard to conclude the association of serum adiponectin and progranulin levels according to benign or PTC groups or clinicopathological features of PTC. Nonetheless, we evaluated serum adiponectin levels according to clinicopathological feature in patients with PTC. Moreover, this is the first study to evaluate serum progranulin levels in patients with benign thyroid nodule and PTC.

In conclusion, serum adiponectin and progranulin levels did not have significant differences between benign and PTC groups in this study. Serum adiponectin levels in patients with PTC showed no significant differences according to primary tumor size, presence of cervical LN metastasis, ETE, and multifocality. Serum progranulin levels increased significantly in patients with PTC $>1 \mathrm{~cm}$. The proportions of patients with microscopic and gross ETE increased significantly according to serum progranulin level quartiles.

\section{CONFLICTS OF INTEREST}

No potential conflict of interest relevant to this article was reported.

\section{ACKNOWLEDGMENTS}

This study was supported by a 2012 Moonsuk Research Grant from the Korean Society for the Study of Obesity (KSSO) and by a grant (No. KBS11082) from Kangbuk Samsung Hospital, Seoul, Korea.

\section{AUTHOR CONTRIBUTIONS}

Conception or design: J.S.Y., C.Y.P. Acquisition, analysis, or interpretation of data: H.K., C.Y.P. Drafting the work or revising: H.K. Final approval of the manuscript: S.E.P., J.S.Y., C.Y.P.

\section{ORCID}

Hyemi Kwon https://orcid.org/0000-0003-4257-3133

Cheol-Young Park https://orcid.org/0000-0002-9415-9965

\section{REFERENCES}

1. Marcello MA, Cunha LL, Batista FA, Ward LS. Obesity and thyroid cancer. Endocr Relat Cancer 2014;21:T255-71.

2. De Pergola G, Silvestris F. Obesity as a major risk factor for cancer. J Obes 2013;2013:291546.

3. Wolin KY, Carson K, Colditz GA. Obesity and cancer. Oncologist 2010;15:556-65.

4. Renehan AG, Tyson M, Egger M, Heller RF, Zwahlen M. Body-mass index and incidence of cancer: a systematic review and meta-analysis of prospective observational studies. Lancet 2008;371:569-78.

5. Xu L, Port M, Landi S, Gemignani F, Cipollini M, Elisei R, et al. Obesity and the risk of papillary thyroid cancer: a pooled analysis of three case-control studies. Thyroid 2014; 24:966-74.

6. Han JM, Kim TY, Jeon MJ, Yim JH, Kim WG, Song DE, et al. Obesity is a risk factor for thyroid cancer in a large, ultrasonographically screened population. Eur J Endocrinol 2013;168:879-86.

7. Rinaldi S, Lise M, Clavel-Chapelon F, Boutron-Ruault MC, Guillas G, Overvad K, et al. Body size and risk of differentiated thyroid carcinomas: findings from the EPIC study. Int J Cancer 2012;131:E1004-14.

8. Leitzmann MF, Brenner A, Moore SC, Koebnick C, Park Y, Hollenbeck A, et al. Prospective study of body mass index, physical activity and thyroid cancer. Int J Cancer 2010;126: 2947-56.

9. Kitahara CM, McCullough ML, Franceschi S, Rinaldi S, Wolk A, Neta G, et al. Anthropometric factors and thyroid cancer risk by histological subtype: pooled analysis of 22 prospective studies. Thyroid 2016;26:306-18.

10. Kwon H, Han KD, Park CY. Weight change is significantly associated with risk of thyroid cancer: a nationwide population-based cohort study. Sci Rep 2019;9:1546. 
11. Kim WG, Cheng SY. Mechanisms linking obesity and thyroid cancer development and progression in mouse models. Horm Cancer 2018;9:108-16.

12. Pappa T, Alevizaki M. Obesity and thyroid cancer: a clinical update. Thyroid 2014;24:190-9.

13. Balkan F, Onal ED, Usluogullari A, Tuzun D, Ozdemir D, Inancli SS, et al. Is there any association between insulin resistance and thyroid cancer?: a case control study. Endocrine 2014;45:55-60.

14. Pazaitou-Panayiotou K, Polyzos SA, Mantzoros CS. Obesity and thyroid cancer: epidemiologic associations and underlying mechanisms. Obes Rev 2013;14:1006-22.

15. Almquist M, Johansen D, Bjorge T, Ulmer H, Lindkvist B, Stocks T, et al. Metabolic factors and risk of thyroid cancer in the Metabolic syndrome and Cancer project (Me-Can). Cancer Causes Control 2011;22:743-51.

16. Rezzonico JN, Rezzonico M, Pusiol E, Pitoia F, Niepomniszcze H. Increased prevalence of insulin resistance in patients with differentiated thyroid carcinoma. Metab Syndr Relat Disord 2009;7:375-80.

17. Dossus L, Franceschi S, Biessy C, Navionis AS, Travis RC, Weiderpass E, et al. Adipokines and inflammation markers and risk of differentiated thyroid carcinoma: the EPIC study. Int J Cancer 2018;142:1332-42.

18. Mitsiades N, Pazaitou-Panayiotou K, Aronis KN, Moon HS, Chamberland JP, Liu X, et al. Circulating adiponectin is inversely associated with risk of thyroid cancer: in vivo and in vitro studies. J Clin Endocrinol Metab 2011;96:E2023-8.

19. Cheng SP, Liu CL, Hsu YC, Chang YC, Huang SY, Lee JJ. Expression and biologic significance of adiponectin receptors in papillary thyroid carcinoma. Cell Biochem Biophys 2013;65:203-10.

20. Pazaitou-Panayiotou K, Panagiotou G, Polyzos SA, Mantzoros CS. Serum adiponectin and insulin-like growth factor 1 in predominantly female patients with thyroid cancer: association with the histologic characteristics of the tumor. Endocr Pract 2016;22:68-75.

21. Abella V, Pino J, Scotece M, Conde J, Lago F, GonzalezGay MA, et al. Progranulin as a biomarker and potential therapeutic agent. Drug Discov Today 2017;22:1557-64.

22. Matsubara T, Mita A, Minami K, Hosooka T, Kitazawa S, Takahashi $\mathrm{K}$, et al. PGRN is a key adipokine mediating high fat diet-induced insulin resistance and obesity through IL-6 in adipose tissue. Cell Metab 2012;15:38-50.

23. Koo DH, Park CY, Lee ES, Ro J, Oh SW. Progranulin as a prognostic biomarker for breast cancer recurrence in pa- tients who had hormone receptor-positive tumors: a cohort study. PLoS One 2012;7:e39880.

24. Arechavaleta-Velasco F, Perez-Juarez CE, Gerton GL, DiazCueto L. Progranulin and its biological effects in cancer. Med Oncol 2017;34:194.

25. Carlson AM, Maurer MJ, Goergen KM, Kalli KR, Erskine CL, Behrens MD, et al. Utility of progranulin and serum leukocyte protease inhibitor as diagnostic and prognostic biomarkers in ovarian cancer. Cancer Epidemiol Biomarkers Prev 2013;22:1730-5.

26. Demorrow S. Progranulin: a novel regulator of gastrointestinal cancer progression. Transl Gastrointest Cancer 2013;2: 145-51.

27. Tkaczuk KR, Yue B, Zhan M, Tait N, Yarlagadda L, Dai H, et al. Increased circulating level of the survival factor GP88 (progranulin) in the serum of breast cancer patients when compared to healthy subjects. Breast Cancer (Auckl) 2011;5: 155-62.

28. Edelman MJ, Feliciano J, Yue B, Bejarano P, Ioffe O, Reisman D, et al. GP88 (progranulin): a novel tissue and circulating biomarker for non-small cell lung carcinoma. Hum Pathol 2014;45:1893-9.

29. Haugen BR, Alexander EK, Bible KC, Doherty GM, Mandel SJ, Nikiforov YE, et al. 2015 American Thyroid Association management guidelines for adult patients with thyroid nodules and differentiated thyroid cancer: the American Thyroid Association guidelines task force on thyroid nodules and differentiated thyroid cancer. Thyroid 2016;26:1-133.

30. Ahn HS, Kim HJ, Welch HG. Korea's thyroid-cancer “epidemic": screening and overdiagnosis. N Engl J Med 2014; 371:1765-7.

31. Elisei R, Molinaro E, Agate L, Bottici V, Masserini L, Ceccarelli $\mathrm{C}$, et al. Are the clinical and pathological features of differentiated thyroid carcinoma really changed over the last 35 years? Study on 4187 patients from a single Italian institution to answer this question. J Clin Endocrinol Metab 2010; 95:1516-27.

32. Davies L, Welch HG. Increasing incidence of thyroid cancer in the United States, 1973-2002. JAMA 2006;295:2164-7.

33. Kim TY, Kim WG, Kim WB, Shong YK. Current status and future perspectives in differentiated thyroid cancer. Endocrinol Metab (Seoul) 2014;29:217-25.

34. Wyatt SB, Winters KP, Dubbert PM. Overweight and obesity: prevalence, consequences, and causes of a growing public health problem. Am J Med Sci 2006;331:166-74.

35. Han SJ, Boyko EJ. The evidence for an obesity paradox in 
type 2 diabetes mellitus. Diabetes Metab J 2018;42:179-87.

36. Vigneri R, Malandrino P, Vigneri P. The changing epidemiology of thyroid cancer: why is incidence increasing? Curr Opin Oncol 2015;27:1-7.

37. Prieto-Hontoria PL, Perez-Matute P, Fernandez-Galilea M, Bustos M, Martinez JA, Moreno-Aliaga MJ. Role of obesity-associated dysfunctional adipose tissue in cancer: a molecular nutrition approach. Biochim Biophys Acta 2011; 1807:664-78.

38. van Kruijsdijk RC, van der Wall E, Visseren FL. Obesity and cancer: the role of dysfunctional adipose tissue. Cancer Epidemiol Biomarkers Prev 2009;18:2569-78.

39. Barb D, Williams CJ, Neuwirth AK, Mantzoros CS. Adiponectin in relation to malignancies: a review of existing basic research and clinical evidence. Am J Clin Nutr 2007;86: s858-66.

40. Abooshahab R, Yaghmaei P, Ghadaksaz HG, Hedayati M. Lack of association between serum adiponectin/leptin levels and medullary thyroid cancer. Asian Pac J Cancer Prev 2016; 17:3861-4. 